\title{
Variations in the Vesicular Monoamine Transporter I Gene (VMATI/SLCI8AI) are Associated with Bipolar I Disorder
}

\author{
Falk W Lohoff*,', John P Dahl', Thomas N Ferraro', Steven E Arnold', Jürgen Gallinat ${ }^{2}$, Thomas Sander ${ }^{3}$ \\ and Wade H Berrettini'
}

'Department of Psychiatry, University of Pennsylvania, Philadelphia, PA, USA; ${ }^{2}$ Clinic for Psychiatry and Psychotherapy, Charité University

Medicine Berlin, Berlin, Germany; ${ }^{3}$ Max-Delbrück-Center, Gene Mapping Center, Berlin, Germany

\begin{abstract}
The vesicular monoamine transporter I gene (VMATI/SLCI8AI) maps to the shared bipolar disorder (BPD)/schizophrenia (SZ) susceptibility locus on chromosome $8 \mathrm{p} 21$. Vesicular monoamine transporters are involved in transport of monoamine neurotransmitters which have been postulated to play a relevant role in the etiology of BPD and/or SZ. Variations in the VMATI gene might affect transporter function and/or expression and might be involved in the etiology of BPD and/or SZ. Genotypes of 585 patients with BPD type I and 563 control subjects were obtained for three missense single nucleotide polymorphisms (SNPs) (Thr4Pro, Thr98Ser, Thr I 36lle) and four non-coding SNPs (rs9887|3, rs2279709, rs3735835, rs 1497020). All cases and controls were of European descent. Allele frequencies differed significantly for the potential functional polymorphism Thrl36Ser between BPD patients and controls $(p=0.003 ; \mathrm{df}=1 ; \mathrm{OR}=1.34 ; 95 \% \mathrm{Cl}: \mathrm{I} .1 \mathrm{I}-1.62)$. Polymorphisms in the promoter region $(\mathrm{rs} 9887 \mathrm{I} 3: p=0.005, \mathrm{df}=1 ; \mathrm{OR}=1.31 ; 95 \%$ Cl: I.09-1.59) and intron 8 (rs2279709: $p=0.039, \mathrm{df}=1 ; \mathrm{OR}=0.84 ; 95 \% \mathrm{Cl}: 0.7 \mathrm{I}-0.99)$ were also associated with disease. Expression analysis confirmed that VMATI is expressed in human brain at the mRNA and protein level. Results suggest that variations in the VMATI gene may confer susceptibility to BPD in patients of European descent. Additional studies are necessary to confirm this effect and to elucidate the role of VMATI in central nervous system physiology.

Neuropsychopharmacology (2006) 31, 2739-2747. doi:10.1038/sj.npp. I30 I 196; published online 23 August 2006
\end{abstract}

Keywords: bipolar disorder; schizophrenia; linkage; association; VMATI; SLCI8AI

\section{INTRODUCTION}

Bipolar disorder (BPD) is a common psychiatric illness that affects approximately $1 \%$ of the general population and is characterized by recurrent episodes of mania and depression. Family, adoption, and twin studies show that BPD has a strong heritable component (Craddock and Jones, 1999; Smoller and Finn, 2003); however, genetic causes have been difficult to elucidate due to the complex mode of inheritance and genetic heterogeneity. Recent linkage studies have suggested that a susceptibility locus for BPD exists on chromosome 8p21-22 (Cichon et al, 2001; Ophoff et al, 2002; Park et al, 2004; Cheng et al, 2006). Interestingly, numerous linkage studies in schizophrenia (SZ) report a susceptibility locus on 8p21 (Pulver et al, 1995, 2000;

\footnotetext{
*Correspondence: Dr FW Lohoff, Department of Psychiatry, Translational Research Laboratory, Center for Neurobiology and Behavior, University of Pennsylvania School of Medicine, 125 South 31st Street, Philadelphia, PA 19104, USA, Tel: + I 215573 4582, Fax: + I 215573 204 I, E-mail: lohoff@mail.med.upenn.edu

Received 21 February 2006; revised II July 2006; accepted 17 July 2006

Online publication: 21 July 2006 at http://www.acnp.org/citations/ Npp072106060 I 21/default.pdf
}

Kendler et al, 1996; Straub et al, 1996; Blouin et al, 1998; Brzustowicz et al, 1999; Gurling et al, 2001; Stefansson et al, 2002; Lewis et al, 2003; Suarez et al, 2006) and a candidate gene from this region, neuregulin 1 (NRG1), was associated with SZ (Stefansson et al, 2002, 2003; Williams et al, 2003; Yang et al, 2003; Corvin et al, 2004; Li et al, 2004; Tang et al, 2004; Petryshen et al, 2005); however, NRG1 is located about $10-15 \mathrm{cM}$ away from the major linkage peaks and others could not confirm an association between the NRG1 gene and SZ (Bakker et al, 2004; Hong et al, 2004; Iwata et al, 2004; Thiselton et al, 2004; Duan et al, 2005; Liu et al, 2005). The report of multiple linkage studies in BPD and SZ supports the hypothesis of a shared susceptibility locus for BPD and SZ on 8p (Berrettini, 2003, 2004). This is especially remarkable since recent BPD linkage analyses found a peak on $8 \mathrm{p}$ in BPD patients with psychotic symptoms (Park et al, 2004; Cheng et al, 2006), suggesting that the phenotype of psychosis might influence susceptibility to BPD and SZ.

The vesicular monoamine transporter 1 gene (VMAT1), also known as SLC18A1, maps to this shared BPD/SZ susceptibility locus on chromosome 8p21 (Peter et al, 1993; Roghani et al, 1996). Vesicular monoamine transporters (VMATs) are involved in the packaging of dopamine, serotonin, adrenalin, and noradrenalin from the cytoplasm 
to their storage vesicles in presynaptic terminals. The vesicles ultimately discharge transmitters into the synaptic cleft by exocytosis following an action potential. Two different isoforms of the transporter are known, VMAT1 and VMAT2, both encoded by different genes (Peter et al, 1993). It was reported initially that VMAT1 is expressed exclusively in peripheral neurons and endocrine tissue and only the VMAT2 isoform was thought to be expressed in brain (Peter et al, 1995; Erickson et al, 1996; Eiden et al, 2004); however, other studies show that VMAT1 is expressed in rat brain (Hansson et al, 1998). Dysregulation of dopamine and serotonin neurotransmission has been long postulated to play a role in the etiology of BPD and SZ (Manji and Lenox, 2000; Tamminga and Holcomb, 2005), thus making VMAT1 a positional and functional candidate gene for these neuropsychiatric disorders.

Studies in vitro show that lithium and valproate, effective pharmacotherapies for BPD, increase the expression of VMAT1 (Cordeiro et al, 2000, 2002, 2004), suggesting that the VMAT1 gene might be a target for therapeutic drug action. Variations in the VMAT1 gene might alter transporter function and/or expression and therefore might play a direct role in the etiology of psychiatric disorders. Indirect evidence that the VMAT is involved in psychiatric disorders stems from positron emission tomography (PET) imaging studies. Binding of radiolabled dihydrotetrabenazine, a catecholamine depleter with higher VMAT2 than VMAT1 affinity (DaSilva et al, 1993, 1994) was increased in thalamus and brainstem of BPD patients when compared to controls (Zubieta et al, 2000). Ventral brainstem binding was higher in BPD and SZ patients compared to controls (Zubieta et al, 2001). These experiments suggest that higher levels of VMAT expression may represent a trait-related abnormality in patients with BPD and SZ. In this study, we test the hypothesis that VMAT1 is expressed in human brain and that variations in the VMAT1/SLC18A1 gene confer susceptibility to BPD.

\section{MATERIALS AND METHODS}

\section{Subjects}

Five hundred and eighty-five unrelated BPD type I patients participated in this study. Patients were collected at centers involved in the National Institute of Mental Health (NIMH) Genetics Initiative on BPD (http://zork.wustl.edu/nimh/ bp.html) and carried a diagnosis of BPD type I as defined by DSM-IV criteria. The key criterion for admission of a family to the study was a diagnosis of BPD type I in two or more siblings. Background and detailed methodology for the NIMH Genetics Initiative are described elsewhere (Dick et al, 2003). All subjects were assessed with the Diagnostic Instrument for Genetic Studies (Nurnberger et al, 1994). Family history information was obtained through the Family Interview for Genetic Studies (FIGS) and medical records were requested. Final best estimate diagnosis was made using all available information including medical records, information from relatives, and the DIGS interview, by two independent senior diagnosticians adhering to DSM-IV criteria. The patient group consisted of $38 \%$ males and $62 \%$ females. The average age at recruitment was 41.6 years. Psychotic symptoms were present in $66 \%$ of the probands at some point during their illness. Psychosis was defined as presence of auditory/visual hallucinations and/or paranoid or bizarre delusions.

The control subjects comprised 563 unrelated healthy individuals with no history of psychiatric or chronic neurological disease. The control group consisted of $51 \%$ males and $49 \%$ females with an average age of 38.5 years at recruitment. All cases and controls were of European descent. Informed consent was obtained from all individuals in accordance with Institutional Review Board (IRB) procedures.

\section{DNA Analyses}

The VMAT1/SLC18A1 gene encodes 525 amino acids and consists of 16 exons spanning $38346 \mathrm{bp}$. Review of the public database (http://www.ncbi.nlm.nih.gov/SNP), the Celera database (http://myscience.appliedbiosystems.com), and the literature revealed 13 non-synonymous and 10 synonymous single nucleotide polymorphisms (SNPs) in the coding region of the SLC18A1 gene and at least 211 noncoding SNPs (Accession \# NM 003053). SNPs for genotyping were chosen based on availability of Applied Biosystems Inc. (ABI) SNP assays, location in the gene, and allele frequencies (Figure 1). Genotyping of three of the nonsynonymous SNPs (Thr4Pro, Thr98Ser, Thr136Ile) and four intronic SNPs across the VMAT1/SLC18A1 gene, was performed using the ABI 'Assays-on-demand' (ABI, Foster City, CA, USA) SNP genotyping assay as per the manufacturer's protocol. $\mathrm{SNP} 1=\mathrm{rs} 988713 ; \quad \mathrm{SNP} 2=\mathrm{rs} 2270641$ (Thr4Pro); SNP3 = rs2270637 (Thr98Ser); SNP4 = rs1390938

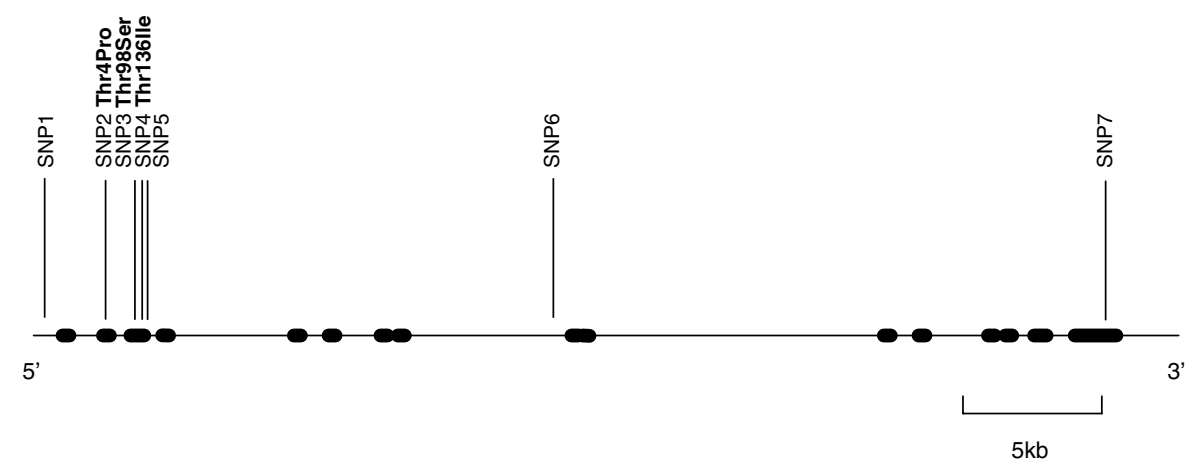

Figure I Variations in the VMATI/SLCI8AI gene. 
(Thr136Ile); SNP5 $=$ rs2279709; SNP6 $=$ rs3735835; SNP7 $=$ rs1497020.

Three additional missense mutations, rs17092144 (Gln11Arg), rs17840571 (Arg140Gly), and rs17092104 (Leu392Val) were genotyped in a subset of patients $(n=94)$ and controls $(n=190)$; however, because of low minor allele frequencies $(<5 \%)$, these markers were not investigated in the entire sample. Genotyping failure rates for all markers were less then $1 \%$ for controls and probands. Accuracy of genotyping was ensured by independent genotyping of a subgroup of the sample at the University of Pennsylvania DNA Core Facility. Concordance rates were greater than $99.5 \%$.

\section{Statistical Analyses}

Genotypes and allele frequencies were compared between groups using $\chi^{2}$ contingency analysis. A two-tailed type I error rate of $5 \%$ was chosen for the analysis. Linkage disequilibrium (LD) and haplotype frequencies were estimated using the COCAPHASE program (Dudbridge, 2003). The COCAPHASE program uses standard unconditional logistic regression analysis. Correction for multiple testing was performed using permutation correction by the COCAPHASE program. This approach corrects for multiple testing but takes into account the correlation between markers. It is thus less conservative than a Bonferroni correction, which is appropriate for independent tests such as unlinked markers. For the single-marker analyses, 10000 permutations were carried out to estimate the significance of the best results, correcting for the seven loci tested. Haplotype analysis was performed using a 4 and 6 sliding marker window. Rare haplotypes were excluded from analysis since the EM algorithm does not accurately estimate haplotype frequencies $<1 \%$ (Fallin and Schork, 2000). The most significant $p$-value was corrected by permutation analysis as described above.

\section{Expression Analyses}

Commercially available human brain cDNA was purchased from Clontech Laboratories Inc. (amygdala, hippocampus, substantia nigra) and Invitrogen Corporation (adult frontal lobe, thalamus, fetal frontal lobe). Expression assays for VMAT1 and VMAT2 were chosen based on specificity after sequence alignment of both mRNAs (VMAT1: ABI assay ID: Hs_0091591, NM 003053, 2749 bp; VMAT2: ABI assay ID: Hs_00161858, NM 003054, $1898 \mathrm{bp}$ ). GAPDH was used as a normalizer (ABI assay ID: Hs_9999905). To avoid possible genomic DNA amplification, probes were designed so that they cross exon-exon junctions. Real-time quantitative PCR using $2 \mathrm{ng}$ of $\mathrm{cDNA}$ per reaction was performed using Applied Biosystems 7300 Sequence Detection System as per the manufacturer's protocol and 'no-template' control samples were included for each assay. Relative quantification was performed using the comparative $C_{\mathrm{T}}$ method $\left(\Delta \Delta C_{\mathrm{T}}\right)$.

Western analysis for VMAT1 was performed using postmortem tissue samples of brain regions and peripheral tissues from an individual who carried a diagnosis of SZ and Alzheimer dementia. The patient died of acute bronchopneumonia and no information was available on the pharmacological regimen before death. Protein was extracted from the frozen samples, fractionated on a $4-12 \%$ gradient Bis-Tris Nu-PAGE gel and transferred to a nitrocellulose filter as outlined above. The membrane was blocked in TBS-T containing 5\% normal donkey serum for $1 \mathrm{~h}$ at room temperature. The membrane was incubated in a 1:100 dilution of an anti-VMAT1 polyclonal antibody (sc-15313, Santa Cruz Biotechnology, Santa Cruz, CA) for $2 \mathrm{~h}$ at room temperature. The blot was washed for 30 min with TBS-T and then incubated with a $1: 10000$ dilution of an anti-goat peroxidase-conjugated secondary antibody (Jackson ImmunoResearch, West Grove, PA). The blot was then washed for $1 \mathrm{~h}$ at room temperature with TBS-T. Western blots were visualized using the Enhanced Chemiluminescence Plus kit (Amersham Biosciences).

An immunohistochemical survey of VMAT1 and VMAT2 in postmortem brain was conducted in sections of hippocampus, entorhinal cortex, hypothalamus, and midbrain-substantia nigra which were labeled with antibodies for VMAT1 (sc-7718, Santa Cruz Biotechnology) or VMAT2 (sc-7722, Santa Cruz Biotechnology). Immunohistochemistry was performed using standard procedures following antigen retrieval by boiling in $1 \mathrm{mM}$ EDTA in $0.1 \mathrm{M}$ Tris buffer, $\mathrm{pH} 8.0$ for $10 \mathrm{~min}$, and using $0.25 \% \mathrm{NiSO} 46 \mathrm{H} 2 \mathrm{O}$ to enhance the diaminobenzidine reaction product, as described previously (Talbot et al, 2004).

\section{RESULTS}

All genotype counts were in Hardy-Weinberg equilibrium. Genotype and allele frequencies for the case-control study are shown in Table 1. The potential functional polymorphism Thr136Ile in VMAT1 was associated with BPD $(p=0.003 ; \mathrm{df}=1 ; \mathrm{OR}=1.34 ; 95 \%$ CI: 1.11-1.62; global significance $p=0.0145$; standard error (SE): 0.001195 after permutation correction). In addition, our results show that two other SNPs in the VMAT1 gene are associated with disease: one SNP in the promoter region (SNP1, rs988713, $-584 \mathrm{~A} / \mathrm{G}, p=0.005, \mathrm{df}=1 ; \mathrm{OR}=1.31 ; 95 \% \mathrm{CI}: 1.09-1.59$ ) and one intronic SNP (SNP6, rs2279709, $p=0.038 ; \mathrm{df}=1$; $\mathrm{OR}=0.86 ; 95 \%$ CI: 0.71-0.99). We observed strong LD in the $5^{\prime}$ end of the gene and perfect LD between markers SNP1 and SNP4 (Table 2). Haplotype analysis shows association with a possible protective haplotype for BPD (Table 3); however, haplotypes do not reach a greater level of statistical significance than the single marker analysis (global significance: $p=0.0196$; SE: 0.001386 ).

Real-time quantitative PCR expression analysis of human brain demonstrates VMAT1 and VMAT2 mRNA in various brain regions (Figure 2). Highest levels were observed for VMAT1 in substantia nigra, followed by amygdala, hippocampus, thalamus, fetal frontal lobe, and frontal lobe. VMAT2 expression was observed highest in substantia nigra.

Western analysis of VMAT1 in postmortem human brain confirms VMAT1 protein expression (Figure 3). VMAT1 immunoreactivity was detected at the expected molecular weight in all brain regions studied, including areas of particular interest in SZ and BPD, such as amygdala, hippocampus, and nucleus accumbens. 
Table I Genotype and Allele Frequencies of Variations in the VMATI/SLCI8AI Gene

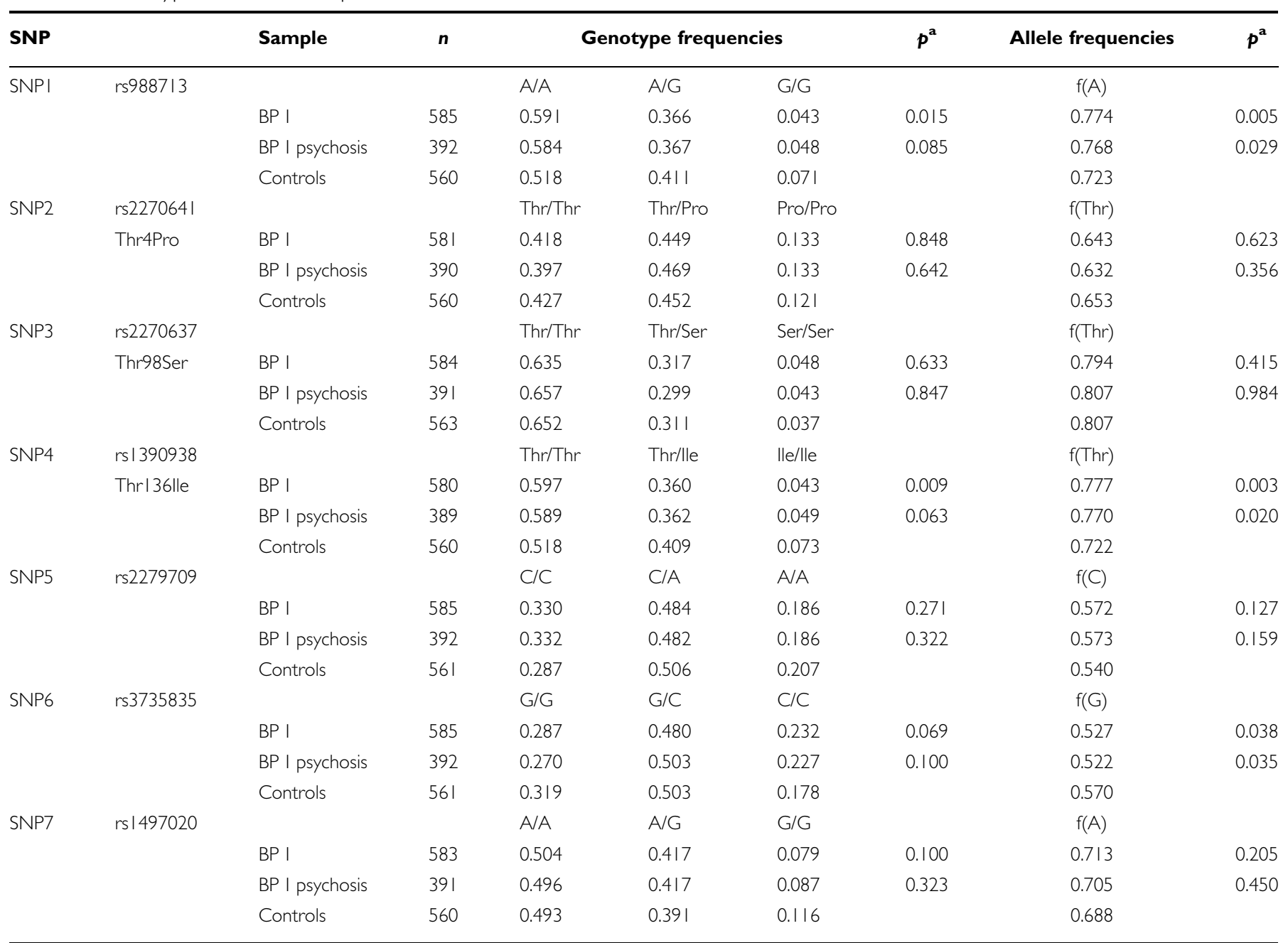

${ }^{a}$ Type-l error rates for comparison of genotype and allele frequencies between bipolar I patients and controls.

Table 2 Linkage Disequilibrium Measures across the VMATI Gene

SNPI SNP2 SNP3 SNP4 SNP5 SNP6 SNP7

\begin{tabular}{lllllllll}
\hline rs988713 & SNPI & - & 1.00 & 1.00 & 1.00 & 1.00 & 1.00 & 0.46 \\
rs227064I & SNP2 & 0.18 & - & 1.00 & 1.00 & 1.00 & 1.00 & 0.49 \\
rs2270637 & SNP3 & 0.08 & 0.13 & - & 1.00 & 1.00 & 1.00 & 0.38 \\
rs1390938 & SNP4 & 1.00 & 0.18 & 0.08 & - & 1.00 & 1.00 & 0.45 \\
rs2279709 & SNP5 & 0.42 & 0.43 & 0.19 & 0.42 & - & 0.53 & 0.42 \\
rs3735835 & SNP6 & 0.27 & 0.65 & 0.20 & 0.27 & 0.19 & - & 0.56 \\
rsI497020 & SNP7 & 0.16 & 0.05 & 0.01 & 0.15 & 0.09 & 0.11 & -
\end{tabular}

Note: $\mathrm{D}^{\prime}$ values are given above the diagonal, and $r^{2}$ values are given below the diagonal.

Immunohistochemistry reveals that VMAT1 and VMAT2 are both expressed in a linear and punctuate pattern typical of axon fibers and terminals in hypothalamus and hippocampal, formation (Figure 4). Similar to the qRTPCR and Western data, we found robust expression of VMAT1 in hypothalamus and hippocampus. The substantia nigra shows heavy VMAT2 innervation, and very little VMAT1 immunoreactivity (data not shown).

\section{DISCUSSION}

In the present study, we show that the potential functional polymorphism Thr136Ile in the VMAT1 gene is associated with BPD. In addition, our results suggest that two other SNPs in the VMAT1 gene may be associated with disease: one SNP in the promoter region (SNP1, rs988713) and one intronic SNP (SNP6, rs2279709). We observed strong LD in the $5^{\prime}$ end of the gene and weaker coverage in the $3^{\prime}$ end of the gene. All three associated SNPs appear to be in one haplotype block and no information is available on their functional effects. Due to the strong LD between markers, additional studies are necessary to elucidate the relevance of the tested variations. Haplotype analysis reveals association with a possible protective haplotype for BPD; however, haplotypes do not reach a greater level of statistical significance than the single marker analysis. The common variations, Thr98Ser and Thr136Ile, are located in the intravesicular loop 1 . This region of the protein interacts 
Table 3 Analysis of Common Haplotypes of SNPI-6 in the VMATI Gene

\begin{tabular}{lcccccc}
\hline Haplotype & Case & Frequency & Control & Frequency & OR & $\boldsymbol{\chi}^{\mathbf{2}}$ \\
\hline A-Thr-Thr-Thr-A-G & 113 & 0.102 & 108.3 & 0.100 & 1 & 0.031 \\
A-Thr-Thr-Thr-A-C & 114 & 0.103 & 88.71 & 0.081 & 0.858 \\
A-Thr-Ser-Thr-C-G & 225 & 0.203 & 206 & 0.190 & 1.232 & 2.945 \\
A-Pro-Thr-Thr-C-C & 401 & 0.363 & 376 & 0.347 & 0.086 \\
G-Thr-Thr-lle-A-G & 251 & 0.227 & 303 & 0.280 & 1.022 & 0.621 \\
\hline
\end{tabular}

${ }^{a}$ Global significance: $p=0.0196$; SE: 0.001386 .

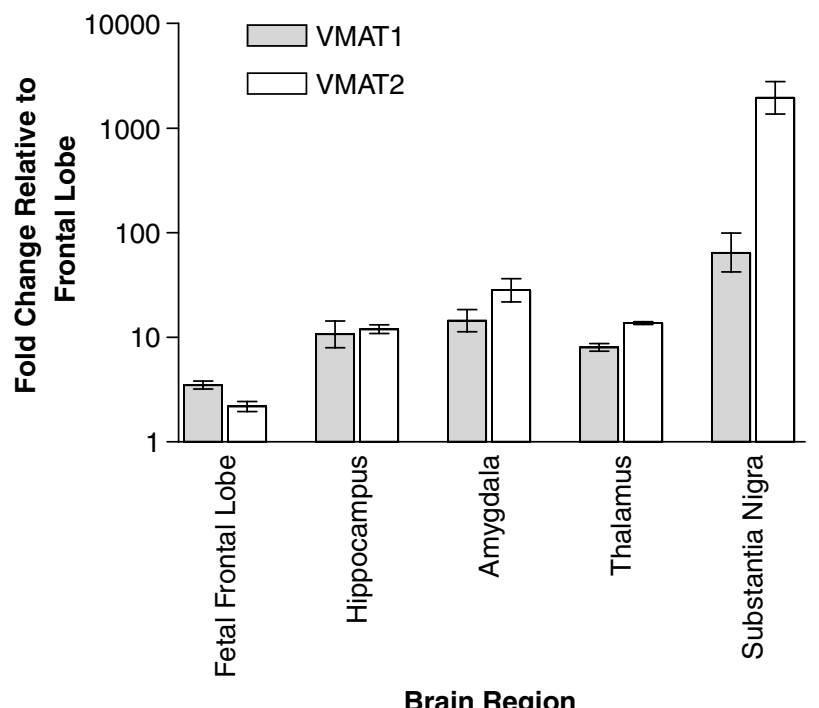

Figure 2 Real-time quantitative PCR determination of mRNA levels for VMATI and VMAT2 in human brain regions. Data shown as mean + SEM of three independent experiments using the comparative $C_{T}$ method.

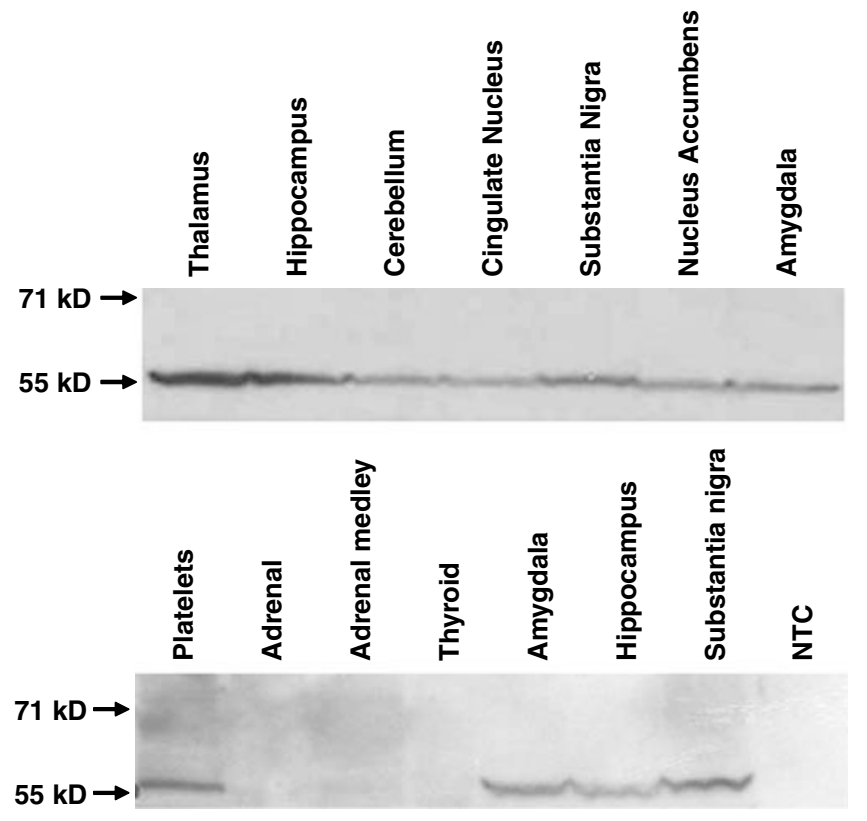

Figure 3 Western blot of human VMATI.

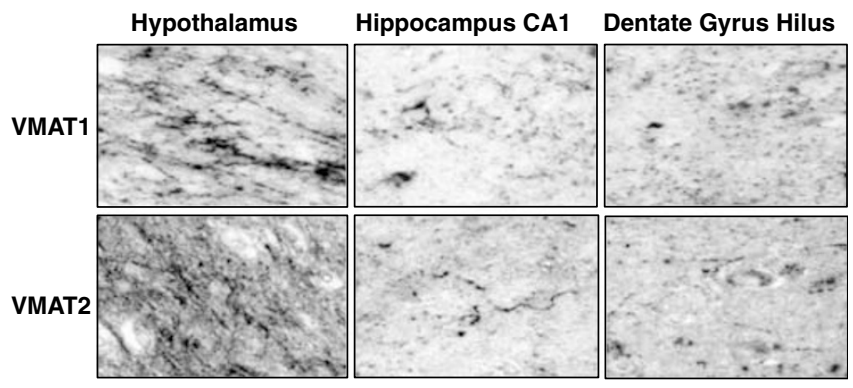

Figure 4 VMATI and VMAT2 immunoreactivity in postmortem human brain.

with both the ligand (inhibitors and substrates) as well as the TMD10/11 region of the transporter (Sievert and Ruoho, 1997). Although no information is available on the biological effect of variants in the VMAT1 gene, and phylogenetic analysis shows no conservation during evolution (data not shown), a direct functional effect of the Thr136Ile or a nearby variant must be considered. In particular, the variation in the promoter region, which is in perfect LD with the Thr136Ile polymorphism, could potentially modulate gene expression; however, functional relevance has not been tested. Increased VMAT1 expression might lead to excessive accumulation of neurotransmitter molecules in vesicles, with subsequent release in the synapse, contributing to mania and psychosis. Reduced VMAT1 expression might lead to insufficient accumulation of neurotransmitters in vesicles, and thus to decreased synaptic levels of neurotransmitters, resulting in depression. This hypothesis is consistent with evidence that reserpine, a VMAT inhibitor that depletes catecholamines, can precipitate episodes of depression and is used in animal models of depression (Slattery et al, 2004).

Expression analysis reveals that VMAT1 is widely expressed in human brain, in particular in substantia nigra, hippocampus, thalamus, amygdala, and frontal lobe at the mRNA and protein level. This finding of VMAT1 expression in human brain is novel and contrary to previous reports (Peter et al, 1995; Erickson et al, 1996; Eiden et al, 2004) in which only VMAT2 was detected in brain. We used realtime PCR to detect VMAT1 mRNA in multiple brain regions. This method has been shown to detect minute amounts of mRNA and is more sensitive then other methods, with the advantage of being less observerdependent (Nakamura et al, 2003; Benoy et al, 2004). Differences in methodological approach might explain the 
discrepancy in findings as previous studies of rat and human brain utilized immunohistochemistry and in situ hybridization to analyze expression (Peter et al, 1995; Erickson et al, 1996; Eiden et al, 2004). To confirm VMAT1 expression in brain, we conducted western and immunohistochemistry analysis of postmortem brain tissue using commercially available antibodies with no-cross reactivity. Our experiments provide evidence that VMAT1 is expressed in human brain on the protein level. Previous reports failed to detect VMAT1 protein in brain which might be due to probe/antibody specificity and/or tissue quality. VMAT1 expression in human brain is consistent with detection of VMAT1 in rat brain (Hansson et al, 1998). Furthermore, review of the public database, including expression profile information suggested by analysis of EST counts (UniGene Hs.158322) and microarray expression data (Affymetrix GeneChip Human Genome U95 Set HG-U95A Accession \# GDS181, Merck Rosetta Chip Accession \# GDS833), indicates that VMAT1 is expressed in brain. Our results document coexpression of VMAT1 and VMAT2 in human brain. When comparing mRNA levels of multiple human brain regions between VMAT1 and VMAT2 (Figure 2), levels differed for substantia nigra (higher VMAT2) and fetal frontal lobe (higher VMAT1) but were similar between frontal lobe, hippocampus, and thalamus. Interestingly, VMAT1 was found to be the predominant isoform in some brain regions during rat brain development (Hansson et al, 1998), coinciding with our observation of higher VMAT1 mRNA levels in the fetal frontal lobe when compared to VMAT2. VMAT1 predominance during early neurodevelopment might be important for migration of neurons, development of neurosecretory pathways, and the survival of neurons (Leroux-Nicollet and Costentin, 1998; Verney et al, 2002; Eells, 2003). Variations in the VMAT1 gene might thus alter neurodevelopment and predispose individuals to neuro-psychiatric diseases, consistent with the hypothesis that SZ and BPD are neurodevelopmental disorders (Lewis and Levitt, 2002; Blumberg et al, 2004; Eastwood, 2004). Taken together, our expression experiments provide evidence that VMAT1 is expressed in human brain at the mRNA and protein level. This finding is important as it stands in contrast to the current understanding of VMAT1/VMAT2 expression and could open a new avenue of research in neuropsychiatric disorders.

Our sample of BPD patients had a positive family history of affective disorder as a key criterion for admission, implicating higher genetic loading of the probands and thus a stronger genetic effect of the tested variation; however, no linkage to chromosome $8 \mathrm{p}$ has been reported in this sample (Segurado et al, 2003). Chromosome $8 \mathrm{p}$ has been suggested repeatedly as a linkage region for both $\mathrm{SZ}$ and $\mathrm{BPD}$; however, the underlying genes responsible for the linkage signal remain elusive. NRG1 was identified as one candidate gene from this region and was associated with SZ (Stefansson et al, 2002, 2003; Williams et al, 2003; Yang et al, 2003; Corvin et al, 2004; Li et al, 2004; Tang et al, 2004; Petryshen et al, 2005) and BPD (Green et al, 2005) in some studies but could not be confirmed by others (Bakker et al, 2004; Hong et al, 2004; Iwata et al, 2004; Thiselton et al, 2004; Duan et al, 2005; Liu et al, 2005). This inconsistency might be due to several factors including clinical heterogeneity, population stratification, different haplotype struc- ture between populations, and limited statistical power. Another possibility might be that several candidate genes contribute to the linkage finding in SZ and BPD and furthermore, that several candidate genes are contributing to a clinical phenotype like psychosis, rather then to a DSMIV category. The phenotypic overlap between SZ, schizoaffective disorder, and BPD has been the subject of extensive debate (Craddock and Owen, 2005; Maier et al, 2005) and the possibility of shared underlying pathophysiologic mechanisms in SZ and BPD is further strengthened by convergent molecular genetic data (Berrettini, 2003, 2004). Previous studies have suggested that psychotic BPD may represent a genetically unique subtype (Potash et al, 2001, 2003). Dissection of the patient group into psychotic BPD shows that all three initially associated markers remain statistically significant, despite reduction in sample size by subgrouping. This finding is consistent with the hypothesis that the phenotype of psychosis might contribute to the overall effect and might explain the presence of a shared susceptibility locus for BPD and SZ on chromosome $8 \mathrm{p}$ (Berrettini, 2003, 2004). However, there are no differences in allele frequencies at these SNPs between the psychotic and non-psychotic groups, suggesting that these SNPs do not differentiate these two putative forms of BPD. These results require confirmation in an independent population of patients and controls and studies of VMAT1 in SZ are also warranted. In particular, VMAT1 association studies in a SZ sample with reported linkage to $8 p$ would be a logical extension of this work.

Although we report a positive association between the VMAT1 gene and BPD, it is possible that our finding might be a false positive result due to population stratification. Case-control association studies of subjects with selfreported ancestries are not immune to population stratification (Freedman et al, 2004), even though all cases and controls in this study were of European descent. A more accurate control would be the use of a family-based association design that matches the genotype of an affected offspring with those parental alleles not inherited by the offspring (Spielman and Ewens, 1996). Ultimately, these results require confirmation in an independent population of patients and controls.

In summary, we show that VMAT1 mRNA and protein is present in many human brain regions and SNPs in the VMAT1 gene are associated with BPD. VMAT1 is thus another high ranking candidate gene for $\mathrm{BPD}$ and $\mathrm{SZ}$ on chromosome $8 \mathrm{p}$. Our results require confirmation in other populations and additional studies are necessary to elucidate the role of VMAT1 in the pathophysiology of BPD.

\section{ACKNOWLEDGEMENTS}

This work was supported by the Center for Neurobiology and Behavior, Department of Psychiatry, University of Pennsylvania. Financial support is gratefully acknowledged from National Institutes of Health grants MH59553, MH63876 (to WHB) and R25 MH060490 (to FWL), a grant from the National Alliance for Research on Schizophrenia and Depression (to WHB), a grant from the Tzedakah Foundation (to WHB) and a grant from the Deutsche Forschungsgemeinschaft (Sa434/3-1 to TS). We would like 
to thank Candice Schwebel, Jacqueline Scena, and Andrew Weller for technical assistance and James Potash for help with clinical data on BPD patients.

Data and biomaterials utilized in this study were collected as part of ten projects that participated in the National Institute of Mental Health (NIMH) Bipolar Disorder Genetics Initiative. From 1999 to 2003, the Principal Investigators and Co-Investigators were: Indiana University, Indianapolis, IN, R01 MH59545, John Nurnberger, MD, $\mathrm{PhD}$, Marvin Miller, MD, Elizabeth Bowman, MD, N Leela Rau, MD, P Ryan Moe, MD, Nalini Samavedy, MD, Rif ElMallakh, MD (at University of Louisville), Husseini Manji, MD (at Wayne State University), Debra A Blitz, MD (at Wayne State University), Eric T Meyer, MS, Carrie Smiley, RN, Tatiana Foroud, PhD, Leah Flury, MS, Danielle M Dick, $\mathrm{PhD}$, Howard Edenberg, PhD; Washington University, St Louis, MO, R01 MH059534, John Rice, PhD, Theodore Reich, MD, Allison Goate, PhD, Laura Bierut, MD; Johns Hopkins University, Baltimore, MD, R01 MH59533, Melvin McInnis, MD, J Raymond DePaulo, Jr, MD, Dean F MacKinnon, MD, Francis M Mondimore, MD, James B Potash, MD, Peter P Zandi, PhD, Dimitrios Avramopoulos, Jennifer Payne; University of Pennsylvania, PA, R01 MH59553, Wade Berrettini, MD, PhD; University of California at Irvine, CA, R01 MH60068, William Byerley, MD and Mark Vawter, MD; University of Iowa, IA, R01 MH059548, William Coryell, MD, Raymond Crowe, MD; University of Chicago, IL, R01 MH059535, Elliot Gershon, MD, Judith Badner, PhD, Francis McMahon, MD, Chunyu Liu, PhD, Alan Sanders, MD, Maria Caserta, Steven Dinwiddie, MD, Tu Nguyen, Donna Harakal; University of California at San Diego, CA, R01 MH59567, John Kelsoe, MD, Rebecca McKinney, BA; Rush University, IL, R01 MH059556, William Scheftner, MD, Howard M Kravitz, DO, MPH, Diana Marta, BS, Annette Vaughn-Brown, MSN, RN, Laurie Bederow, MA; NIMH Intramural Research Program, Bethesda, MD, 1Z01MH02810-01, Francis J McMahon, MD, Layla Kassem, PsyD, Sevilla Derta-Wadleigh, PhD, Lisa Austin, PhD, Dennis L Murphy, MD.

Most importantly, we thank the families who have participated in and contributed to these studies.

\section{REFERENCES}

Bakker SC, Hoogendoorn ML, Selten JP, Verduijn W, Pearson PL, Sinke RJ et al (2004). Neuregulin 1: genetic support for schizophrenia subtypes. Mol Psychiatry 9: 1061-1063.

Benoy IH, Elst H, Van der Auwera I, Van Laere S, van Dam P, Van Marck E et al (2004). Real-time RT-PCR correlates with immunocytochemistry for the detection of disseminated epithelial cells in bone marrow aspirates of patients with breast cancer. Br J Cancer 91: 1813-1820.

Berrettini W (2003). Evidence for shared susceptibility in bipolar disorder and schizophrenia. Am J Med Genet C Semin Med Genet 123: $59-64$.

Berrettini W (2004). Bipolar disorder and schizophrenia: convergent molecular data. Neuromolecular Med 5: 109-117.

Blouin JL, Dombroski BA, Nath SK, Lasseter VK, Wolyniec PS, Nestadt G et al (1998). Schizophrenia susceptibility loci on chromosomes 13q32 and 8p21. Nat Genet 20: 70-73.

Blumberg HP, Kaufman J, Martin A, Charney DS, Krystal JH, Peterson BS (2004). Significance of adolescent neurodevelopment for the neural circuitry of bipolar disorder. Ann NY Acad Sci 1021: 376-383.

Brzustowicz LM, Honer WG, Chow EW, Little D, Hogan J, Hodgkinson $\mathrm{K}$ et al (1999). Linkage of familial schizophrenia to chromosome 13q32. Am J Hum Genet 65: 1096-1103.

Cheng R, Juo SH, Loth JE, Nee J, Iossifov I, Blumenthal R et al (2006). Genome-wide linkage scan in a large bipolar disorder sample from the National Institute of Mental Health genetics initiative suggests putative loci for bipolar disorder, psychosis, suicide, and panic disorder. Mol Psychiatry 11: 252-260.

Cichon S, Schumacher J, Muller DJ, Hurter M, Windemuth C, Strauch $\mathrm{K}$ et al (2001). A genome screen for genes predisposing to bipolar affective disorder detects a new susceptibility locus on 8q. Hum Mol Genet 10: 2933-2944.

Cordeiro ML, Gundersen CB, Umbach JA (2002). Lithium ions modulate the expression of VMAT2 in rat brain. Brain Res 953: 189-194.

Cordeiro ML, Gundersen CB, Umbach JA (2004). Convergent effects of lithium and valproate on the expression of proteins associated with large dense core vesicles in NGF-differentiated PC12 cells. Neuropsychopharmacology 29: 39-44.

Cordeiro ML, Umbach JA, Gundersen CB (2000). Lithium ions up-regulate mRNAs encoding dense-core vesicle proteins in nerve growth factor-differentiated PC12 cells. J Neurochem 75: $2622-2625$.

Corvin AP, Morris DW, McGhee K, Schwaiger S, Scully P, Quinn J et al (2004). Confirmation and refinement of an 'at-risk' haplotype for schizophrenia suggests the EST cluster, Hs.97362, as a potential susceptibility gene at the neuregulin-1 locus. Mol Psychiatry 9: 208-213.

Craddock N, Jones I (1999). Genetics of bipolar disorder. J Med Genet 36: 585-594.

Craddock N, Owen MJ (2005). The beginning of the end for the Kraepelinian dichotomy. Br J Psychiatry 186: 364-366.

DaSilva JN, Carey JE, Sherman PS, Pisani TJ, Kilbourn MR (1994). Characterization of $\left[{ }^{11} \mathrm{C}\right]$ tetrabenazine as an in vivo radioligand for the vesicular monoamine transporter. Nucl Med Biol 21: 151-156.

DaSilva JN, Kilbourn MR, Mangner TJ (1993). Synthesis of a $\left[{ }^{11} \mathrm{C}\right]$ methoxy derivative of alpha-dihydrotetrabenazine: a radioligand for studying the vesicular monoamine transporter. Appl Radiat Isot 44: 1487-1489.

Dick DM, Foroud T, Flury L, Bowman ES, Miller MJ, Rau NL et al (2003). Genomewide linkage analyses of bipolar disorder: a new sample of 250 pedigrees from the National Institute of Mental Health Genetics Initiative. Am J Hum Genet 73: $107-114$.

Duan J, Martinez M, Sanders AR, Hou C, Krasner AJ, Schwartz DB et al (2005). Neuregulin 1 ( NRG1) and schizophrenia: analysis of a US family sample and the evidence in the balance. Psychol Med 35: 1599-1610.

Dudbridge F (2003). Pedigree disequilibrium tests for multilocus haplotypes. Genet Epidemiol 25: 115-121.

Eastwood SL (2004). The synaptic pathology of schizophrenia: is aberrant neurodevelopment and plasticity to blame? Int Rev Neurobiol 59: 47-72.

Eells JB (2003). The control of dopamine neuron development, function and survival: insights from transgenic mice and the relevance to human disease. Curr Med Chem 10: 857-870.

Eiden LE, Schafer MK, Weihe E, Schutz B (2004). The vesicular amine transporter family (SLC18): amine/proton antiporters required for vesicular accumulation and regulated exocytotic secretion of monoamines and acetylcholine. Pflugers Arch 447: 636-640.

Erickson JD, Schafer MK, Bonner TI, Eiden LE, Weihe E (1996). Distinct pharmacological properties and distribution in neurons and endocrine cells of two isoforms of the human vesicular monoamine transporter. Proc Natl Acad Sci USA 93: 5166-5171. 
Fallin D, Schork NJ (2000). Accuracy of haplotype frequency estimation for biallelic loci, via the expectation-maximization algorithm for unphased diploid genotype data. Am J Hum Genet 67: 947-959.

Freedman ML, Reich D, Penney KL, McDonald GJ, Mignault AA, Patterson $\mathrm{N}$ et al (2004). Assessing the impact of population stratification on genetic association studies. Nat Genet 36: $388-393$.

Green EK, Raybould R, Macgregor S, Gordon-Smith K, Heron J, Hyde $S$ et al (2005). Operation of the schizophrenia susceptibility gene, neuregulin 1, across traditional diagnostic boundaries to increase risk for bipolar disorder. Arch Gen Psychiatry 62: 642-648.

Gurling HM, Kalsi G, Brynjolfson J, Sigmundsson T, Sherrington $\mathrm{R}$, Mankoo BS et al (2001). Genomewide genetic linkage analysis confirms the presence of susceptibility loci for schizophrenia, on chromosomes 1q32.2, 5q33.2, and 8p21-22 and provides support for linkage to schizophrenia, on chromosomes 11q23.3-24 and 20q12.1-11.23. Am J Hum Genet 68: 661-673.

Hansson SR, Hoffman BJ, Mezey E (1998). Ontogeny of vesicular monoamine transporter mRNAs VMAT1 and VMAT2. I. The developing rat central nervous system. Brain Res Dev Brain Res 110: $135-158$.

Hong CJ, Huo SJ, Liao DL, Lee K, Wu JY, Tsai SJ (2004). Casecontrol and family-based association studies between the neuregulin 1 (Arg38Gln) polymorphism and schizophrenia. Neurosci Lett 366: 158-161.

Iwata N, Suzuki T, Ikeda M, Kitajima T, Yamanouchi Y, Inada T et al (2004). No association with the neuregulin 1 haplotype to Japanese schizophrenia. Mol Psychiatry 9: 126-127.

Kendler KS, MacLean CJ, O’Neill FA, Burke J, Murphy B, Duke F et al (1996). Evidence for a schizophrenia vulnerability locus on chromosome $8 \mathrm{p}$ in the Irish Study of High-Density Schizophrenia Families. Am J Psychiatry 153: 1534-1540.

Leroux-Nicollet I, Costentin J (1998). Transient expression of the vesicular monoamine transporter during development in the rat thalamus and cortex. Neurosci Lett 248: 167-170.

Lewis CM, Levinson DF, Wise LH, DeLisi LE, Straub RE, Hovatta I et al (2003). Genome scan meta-analysis of schizophrenia and bipolar disorder, part II: schizophrenia. Am J Hum Genet 73: 34-48.

Lewis DA, Levitt P (2002). Schizophrenia as a disorder of neurodevelopment. Annu Rev Neurosci 25: 409-432.

Li T, Stefansson H, Gudfinnsson E, Cai G, Liu X, Murray RM et al (2004). Identification of a novel neuregulin 1 at-risk haplotype in Han schizophrenia Chinese patients, but no association with the Icelandic/Scottish risk haplotype. Mol Psychiatry 9: 698-704.

Liu CM, Hwu HG, Fann CS, Lin CY, Liu YL, Ou-Yang WC et al (2005). Linkage evidence of schizophrenia to loci near neuregulin 1 gene on chromosome $8 \mathrm{p} 21$ in Taiwanese families. Am J Med Genet B Neuropsychiatr Genet 134: 79-83.

Maier W, Hofgen B, Zobel A, Rietschel M (2005). Genetic models of schizophrenia and bipolar disorder: overlapping inheritance or discrete genotypes? Eur Arch Psychiatry Clin Neurosci 255: 159-166.

Manji HK, Lenox RH (2000). Signaling: cellular insights into the pathophysiology of bipolar disorder. Biol Psychiatry 48: 518-530.

Nakamura H, Saji H, Idiris A, Kawasaki N, Hosaka M, Ogata A et al (2003). Comparison of immunohistochemistry and real-time reverse transcription-polymerase chain reaction to detect expression of carcinoembryonic antigen in lung cancer. Oncol Rep 10: 1231-1235.

Nurnberger Jr JI, Blehar MC, Kaufmann CA, York-Cooler C, Simpson SG, Harkavy-Friedman J et al (1994). Diagnostic interview for genetic studies. Rationale, unique features, and training. NIMH Genetics Initiative. Arch Gen Psychiatry 51: 849-859 (discussion 863-864).

Ophoff RA, Escamilla MA, Service SK, Spesny M, Meshi DB, Poon $\mathrm{W}$ et al (2002). Genomewide linkage disequilibrium mapping of severe bipolar disorder in a population isolate. Am J Hum Genet 71: $565-574$.

Park N, Juo SH, Cheng R, Liu J, Loth JE, Lilliston B et al (2004). Linkage analysis of psychosis in bipolar pedigrees suggests novel putative loci for bipolar disorder and shared susceptibility with schizophrenia. Mol Psychiatry 9: 1091-1099.

Peter D, Finn JP, Klisak I, Liu Y, Kojis T, Heinzmann C et al (1993). Chromosomal localization of the human vesicular amine transporter genes. Genomics 18: 720-723.

Peter D, Liu Y, Sternini C, de Giorgio R, Brecha N, Edwards RH (1995). Differential expression of two vesicular monoamine transporters. J Neurosci 15: 6179-6188.

Petryshen TL, Middleton FA, Kirby A, Aldinger KA, Purcell S, Tahl $\mathrm{AR}$ et al (2005). Support for involvement of neuregulin 1 in schizophrenia pathophysiology. Mol Psychiatry 10: 328.

Potash JB, Chiu YF, MacKinnon DF, Miller EB, Simpson SG, McMahon FJ et al (2003). Familial aggregation of psychotic symptoms in a replication set of 69 bipolar disorder pedigrees. Am J Med Genet B Neuropsychiatr Genet 116: 90-97.

Potash JB, Willour VL, Chiu YF, Simpson SG, MacKinnon DF, Pearlson GD et al (2001). The familial aggregation of psychotic symptoms in bipolar disorder pedigrees. Am J Psychiatry 158: $1258-1264$.

Pulver AE, Lasseter VK, Kasch L, Wolyniec P, Nestadt G, Blouin JL et al (1995). Schizophrenia: a genome scan targets chromosomes $3 \mathrm{p}$ and $8 \mathrm{p}$ as potential sites of susceptibility genes. Am J Med Genet 60: 252-260.

Pulver AE, Mulle J, Nestadt G, Swartz KL, Blouin JL, Dombroski B et al (2000). Genetic heterogeneity in schizophrenia: stratification of genome scan data using co-segregating related phenotypes. Mol Psychiatry 5: 650-653.

Roghani A, Welch C, Xia Y, Liu Y, Peter D, Finn JP et al (1996). Assignment of the mouse vesicular monoamine transporter genes, Slc18a1 and Slc18a2, to chromosomes 8 and 19 by linkage analysis. Mamm Genome 7: 393-394.

Segurado R, Detera-Wadleigh SD, Levinson DF, Lewis CM, Gill M, Nurnberger Jr JI et al (2003). Genome scan meta-analysis of schizophrenia and bipolar disorder, part III: bipolar disorder. Am J Hum Genet 73: 49-62.

Sievert MK, Ruoho AE (1997). Peptide mapping of the $\left[{ }^{125} \mathrm{I}\right] \mathrm{Io}-$ doazidoketanserin and $\left[{ }^{125} \mathrm{I}\right] 2-N-\left[\left(3^{\prime}\right.\right.$-iodo-4'-azidophenyl)propionyl]tetrabenazine binding sites for the synaptic vesicle monoamine transporter. J Biol Chem 272: 26049-26055.

Slattery DA, Hudson AL, Nutt DJ (2004). Invited review: the evolution of antidepressant mechanisms. Fundam Clin Pharmacol 18: 1-21.

Smoller JW, Finn CT (2003). Family, twin, and adoption studies of bipolar disorder. Am J Med Genet C Semin Med Genet 123: 48-58.

Spielman RS, Ewens WJ (1996). The TDT and other family-based tests for linkage disequilibrium and association. Am J Hum Genet 59: 983-989.

Stefansson H, Sarginson J, Kong A, Yates P, Steinthorsdottir V, Gudfinnsson E et al (2003). Association of neuregulin 1 with schizophrenia confirmed in a Scottish population. Am J Hum Genet 72: 83-87.

Stefansson H, Sigurdsson E, Steinthorsdottir V, Bjornsdottir S, Sigmundsson T, Ghosh S et al (2002). Neuregulin 1 and susceptibility to schizophrenia. Am J Hum Genet 71: 877-892.

Straub RE, MacLean CJ, Walsh D, Kendler KS (1996). Support for schizophrenia vulnerability loci on chromosomes $6 \mathrm{p}$ and $8 \mathrm{p}$ from Irish families. Cold Spring Harb Symp Quant Biol 61: 823-833.

Suarez BK, Duan J, Sanders AR, Hinrichs AL, Jin CH, Hou C et al (2006). Genomewide linkage scan of 409 European-ancestry and African American families with schizophrenia: suggestive evidence of linkage at $8 \mathrm{p} 23.3-\mathrm{p} 21.2$ and $11 \mathrm{p} 13.1-\mathrm{q} 14.1$ in the combined sample. Am J Hum Genet 78: 315-333. 
Talbot K, Eidem WL, Tinsley CL, Benson MA, Thompson EW, Smith RJ et al (2004). Dysbindin-1 is reduced in intrinsic, glutamatergic terminals of the hippocampal formation in schizophrenia. J Clin Invest 113: 1353-1363.

Tamminga CA, Holcomb HH (2005). Phenotype of schizophrenia: a review and formulation. Mol Psychiatry 10: 27-39.

Tang JX, Chen WY, He G, Zhou J, Gu NF, Feng GY et al (2004). Polymorphisms within $5^{\prime}$ end of the neuregulin 1 gene are genetically associated with schizophrenia in the Chinese population. Mol Psychiatry 9: 11-12.

Thiselton DL, Webb BT, Neale BM, Ribble RC, O'Neill FA, Walsh D et al (2004). No evidence for linkage or association of neuregulin-1 (NRG1) with disease in the Irish study of highdensity schizophrenia families (ISHDSF). Mol Psychiatry 9: 729.

Verney C, Lebrand C, Gaspar P (2002). Changing distribution of monoaminergic markers in the developing human cerebral cortex with special emphasis on the serotonin transporter. Anat Rec 267: 87-93.

Williams NM, Preece A, Spurlock G, Norton N, Williams HJ, Zammit S et al (2003). Support for genetic variation in neuregulin 1 and susceptibility to schizophrenia. Mol Psychiatry 8: 485-487. Yang JZ, Si TM, Ruan Y, Ling YS, Han YH, Wang XL et al (2003). Association study of neuregulin 1 gene with schizophrenia. Mol Psychiatry 8: 706-709.

Zubieta JK, Huguelet P, Ohl LE, Koeppe RA, Kilbourn MR, Carr JM et al (2000). High vesicular monoamine transporter binding in asymptomatic bipolar I disorder: sex differences and cognitive correlates. Am J Psychiatry 157: 1619-1628.

Zubieta JK, Taylor SF, Huguelet P, Koeppe RA, Kilbourn MR, Frey KA (2001). Vesicular monoamine transporter concentrations in bipolar disorder type I, schizophrenia, and healthy subjects. Biol Psychiatry 49: 110-116. 